\title{
EVENTS WITHIN AN EVENT, UNITS WITHIN A UNIT: EXPLAINING THE STRUCTURE OF URBAN SPACES THROUGH NESTING THEORY
}

\author{
Achmad Hery Fuad ${ }^{1 *}$, Yandi Andri Yatmo ${ }^{1}$, Emirhadi Suganda ${ }^{1}$, Linda Darmajanti Ibrahim ${ }^{2}$ \\ ${ }^{1}$ Department of Architecture, Faculty of Engineering, Universitas Indonesia, Kampus UI Depok, \\ Depok 16424, Indonesia \\ ${ }^{2}$ Department of Sociology, Faculty of Social and Political Sciences, Universitas Indonesia, Kampus \\ UI Depok, Depok 16424, Indonesia
}

(Received: December 2017 / Revised: December 2017 / Accepted: January 2018)

\begin{abstract}
How do we reveal hidden structures within a complicated web of social interactions? How can we explain the complex nexus of relationships in a public space? In this paper, we offer a different perspective on urban structures by using a multi-layer perspective to understand the structure of space that emerges from the complex uses of spaces. We particularly benefit from the concept of nesting as the theoretical lens in our research. We use a popular urban leisure space in Jakarta as a case study: The Hotel Indonesia (HI) Roundabout during Car Free Day Sunday events. We reveal that within this particular event, there are nested smaller events. The nesting structure also demonstrates how events and activities overlap within a single setting. The nesting approach provides us with a chance to seek an alternative structure for urban spaces.
\end{abstract}

Keywords: Nesting; Public space; Structure; Urban

\section{INTRODUCTION}

The current approach of urban design based on modern movement uses geometrical order, separation of urban functions, zoning, and beauty (Corbusier, 1972; Corbusier, 1987; Boyer,1982; Congrès Internationaux d'Architecture Moderne, Declaration of Aims 1928 and Lang, 1994) as design methods and approaches. These approaches are still in practice, as is the post-modern movement that uses integration approaches, mixed use, contextual, history, and vitality (Jacobs, 1961; Charter Machu Picchu 1977 and Lang, 1994; Trancik, 1986; Tibbalds, 2001). Another idea is the semi-lattice structure from Alexander (1965). He asserted that the semi-lattice structure represents the complexity of social relationships that occur in cities. With the semi-lattice structure, it is possible to describe the social relationship as interrelated, without hierarchy, and overlapped.

This research attempts to study the use of urban spaces by city residents by observing the activity at the Hotel Indonesia (HI) Roundabout in Jakarta during Car Free Day (CFD) events every Sunday. Space is used for various events and various actors (Fuad \& Yatmo, 2017). CFD activities can be categorized as a "picnic" because they aim to provide pleasure, happiness, and health (Hern, 1989). The diverse activities at the HI Roundabout are carried out simultaneously and are interrelated and overlapping, as well as being mutually supportive and attractive. This phenomenon brings forth questions about how such overlapping activities are explained.

\footnotetext{
*Corresponding author's email: heryfuad@gmail.com, Tel: +62-217863512, Fax: +62-217863514
} Permalink/DOI: https://dx.doi.org/10.14716/ijtech.v9i1.1014 
How can the phenomenon of a diverse, complex social activity be explained from the perspective of the usage of space, ideas about the structures of space, and the process of the creation of new spaces in the existing urban space?

Alexander's (1965) semi-lattice structure describes the interrelated and complex social activities that occur in cities. It shows the relationships among the entities inside the structure, but it does not explain the presence of the structures inside the structure. Therefore, it cannot fully explore the process of space usage and the transformation of the space inside the other space. It cannot be used to observe the structures inside the structure. No further concepts have emerged since Alexander's semi-lattice structure that can be used to reveal the formation of a city's structure. In this paper, we propose the use of Gibson's (1986) nesting concept to reveal the structures of different urban space uses for activities that are interrelated and overlapping. By using this concept, we expect to fill the gap that exists in our understanding of how the formation of the structure of today's urban space can be explained.

\section{NESTING: AN OVERVIEW}

\subsection{Nesting, Hierarchy, Affordances, and Social Context}

Ideas about nesting were presented by Gibson (1986) with examples in nature, such as valleys, mountains, leaves, and cells. He explained that valleys are nested in mountains, trees are nested in valleys, foliage is nested in trees, and cells are nested in foliage. This phenomenon illustrates the relationship between small units and larger units. The smaller units are embedded in the larger units by what I will call nesting (Gibson, 1986, p.9). Gibson also explained that nesting appears on every level of the environment, which opens up the possibility of a different perspective in studying our environment (Gibson, 1986)

Gibson (1986) also wrote about nesting and hierarchy: "Things are components of other things. They would constitute a hierarchy unless the hierarchy is uncategorized, but it is full of transition and overlaps" (Gibson, 1986, p. 9). This statement suggests that there is a hierarchy in nesting and units can take subordinate and superordinate roles and may also be transitional and overlapping. This is also explained in the means-ends idea of Vicente and Rasmussen (1990). Means-ends or abstraction hierarchies are used to approach a set of similar or almost identical problems. This idea was originally used as an approach to explaining the structural function of a complex work domain. This idea can also describe the relationships among different affordances' variants of the environment (Vicente \& Rasmussen, 1990).

Studies about nesting have also explored its link to social contexts. Wagman et al. (2016) asserted that multiple affordances exist in any given situation. They exist in nested relationships, and perceivers are sensitive to affordances for another person. The presence of a person with his or her activities affects the perceptions and activities of the other people. A person's activity is triggered because his/ her perception arising from the activity of others shows the existence of a nested affordance in one's activities. These social activities become a social context wherein potential activities are nested. The idea of nesting and hierarchy as an explanation of the environment can be used to understand the shifting situation of current urban space structures, and in this paper, it will be used specifically to explain the phenomenon of the urban picnic.

\subsection{Events and Nesting}

Tschumi (1994) emphasized the event configured from uncertainties of unexpected outcomes. According to Tschumi, events reveal the potential of invisibility or contradictions in programs that relate to an extraordinary space configuration. Thus, space configuration creates conditions for unexpected events. Tschumi emphasized the role of space and programs in establishing conditions for the occurrence of events. 
Gibson (1986) discussed ecological events, which are diverse and difficult to establish or formulate. When we intend to reduce them to basic physical events, they become very complex, and then the complexity blinds us from ecological simplicity. Gibson stated that the order of events cannot be changed, but the order of the parts can be changed. Gibson also argued that events are diverse, difficult to form and compose, and complex. Parts of events can be overhauled, but events themselves cannot be changed (Gibson, 1986, p. 101).

There are some similarities between the ideas of events from Gibson (1986) and Tschumi (1994). First, events are uncertain and difficult to establish and formulate. Second, Tschumi saw space and programs as a requirement of the event while Gibson saw that an event needs a space called ecology. Third, Gibson stated that the order of events' parts can be changed, although the event itself cannot be changed, while according to Tschumi, the event can occur in the space with an appropriate space configuration. Changeable orders and appropriate space configurations show a similarity of ideas. This implies that the possibility of changes in the order of an event's parts will obtain an appropriate space configuration, and vice versa, the existing space configuration will change the order and result in different events.

Gibson (1986) also explained the relationship of nesting and events. According to him, events consist of natural units nested in one episode with another episode, superordinate with the subordinate. If we can understand the sequence of nesting, when we see the initial part of an event,it is possible to predict the final part of the event (Gibson, 1986, p. 102).

Through the study of nesting, it can be concluded that first, nesting is an ecological phenomenon. Discussing nesting also means discussing the relationships among units and events. Second, nesting seeks the structure of the things, which are not always the same, and is open to differences. Third, nesting is also related to affordances, because there are multiple affordances in everyday life; one affordance nests in another affordance. Fourth, nesting is also related to hierarchy and sometimes overlaps, as shown by the means-ends approach. Fifth, nesting occurs inside the affordances and in human perception. Nesting as a part of affordances has a link to the social context. Therefore, understanding the notion of nesting opens a way to understand and reveal the relationships as well as the complexity of the social activities of Jakarta urbanites in an urban picnic activity. It provides a chance to seek out the process and the emergence of a new structure of urban spaces. The process is important to answer the question of this research.

\section{METHODOLOGY}

This study used Gibson's (1986) concept of nesting as a theoretical lens. The nesting idea enabled us to see the activities, events, and elements of spaces as units as well as parts of a larger unit. "It is important to realize that smaller units are nested within larger units. There are events within events, as there are forms within forms" (Gibson, 1986, p. 12). The nested approach also provides an opportunity to select the units that will be reviewed or analyzed. "The units you choose for describing the environments depends on the level of the environment you choose to describe" (Gibson, 1986, p. 9). In this research, we looked at the occurrence of smaller units in larger units and the relationships between units. We looked at the events in the event, and the relationships between small events occurring in small units with the larger event. Referring to Vicente and Rasmussen (1990), activities that occur between units show the superordinate and subordinate relationships and hierarchies that exist.

The research was conducted in the Bundaran Hotel Indonesia or the HI Roundabout, one of the most popular places in Jakarta. This urban space is located on the main axis connecting the northern and southern parts of Jakarta called J1. M.H. Thamrin - Jl. Jendral Sudirman. The HI Roundabout is surrounded by tall buildings with commercial functions such as shopping malls, offices, and hotels. Every Sunday from 6:00 to 11:00 a.m., this area is used for Car Free Day 
(CFD) events as declared by Regulation of the Governor of DKI Jakarta Province Number 12 (2016) to provide an opportunity for Jakarta citizens to enjoy the urban space free of motor vehicles.

Observations at the HI Roundabout were conducted periodically. We recorded the activities the visitors were doing and where, when, and how they used the urban space. Observations were carried out on a weekly basis from October 2013 to April 2016 to reveal the types of activities, the actors, and the places of activity. These data show patterns in the use of the space around the HI Roundabout by those attending the CFD events.

\section{FINDINGS}

\subsection{Events Within an Event}

Figure 1 shows the setting of the HI Roundabout on a Sunday morning from 6:00 a.m. to 11:00 a.m. The observation of the CFD event shows that events are occurring within the main event of CFD.

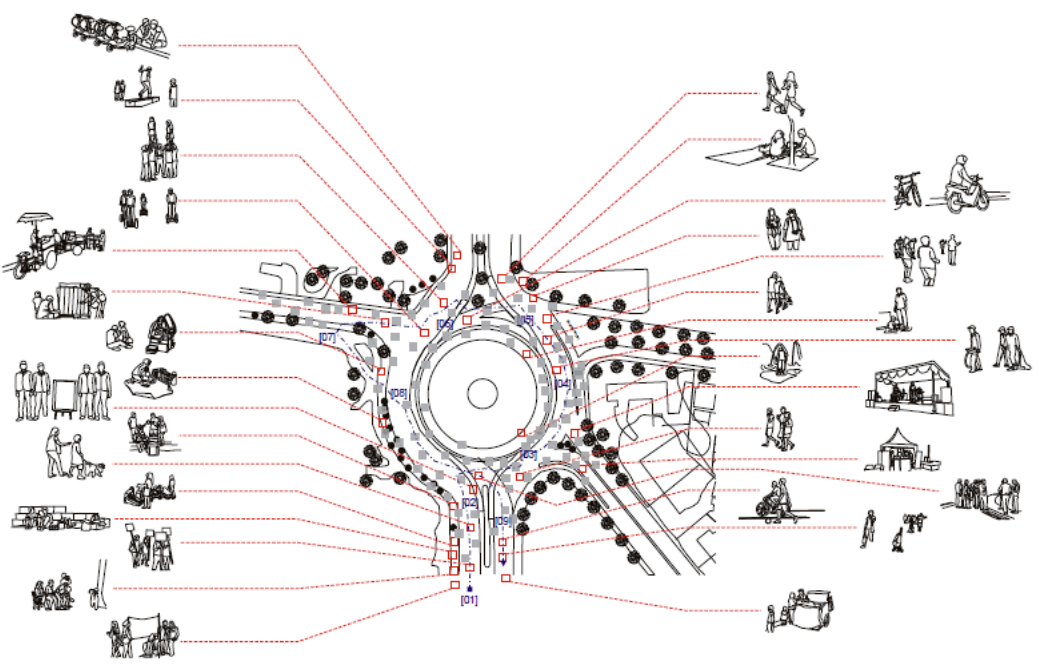

Figure 1 Various events in the HI Roundabout

People are performing various activities, such as sports activities being conducted by teenagers, adults, and children as well as family-related activities such as parenting, playing, chatting, enjoying food and drink, and shopping. Some families go to the CFD event to relax and enjoy the atmosphere. Teenagers and communities often hold many attractions, campaigns, promotional events, and performances while selling food and other merchandise. The observation shows that there are events nested within the main event (Gibson,1986).

\subsection{Small Units within a Larger Unit}

The study found that there were units of activity that were part of larger units. Figure 1 shows that the HI Roundabout consists of various elements of space, such as a pedestrian walkway with borders, benches, trees, pool edges, a street, fences, and the buildings around it. The spatial elements can be seen as smaller units nested in the larger unit of the HI Roundabout space. A variety of events can be seen as small units nested in the larger unit of the CFD event. Without the CFD event, these events would never happen. Various activities or events that occur at the HI Roundabout become the small units nested in the larger unit of the CFD event, illustrating what Gibson (1986) wrote: "The smaller units are embedded in the larger units by what I will call nesting" (Gibson, 1986, p. 9) (Figure 2). 


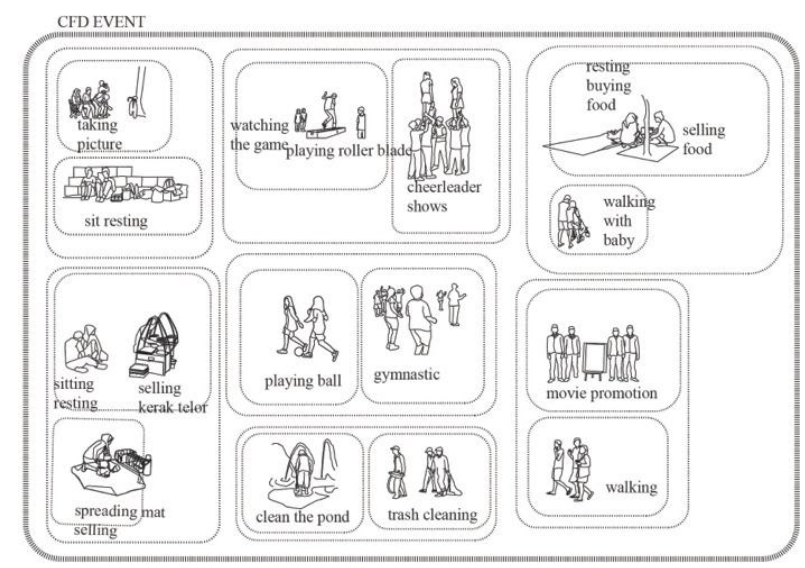

Figure 2 Small units within a larger unit

\subsection{Smaller Units within a Small Unit}

Figure 3 shows photographs of the ontel (ontel is a kind of old and antique bike) bicycle community gathering as one of the events in the CFD event. They gathered on the northwest side of the HI Roundabout. As they gathered, they also showed off their bicycles and this attracted the attention of CFD visitors.

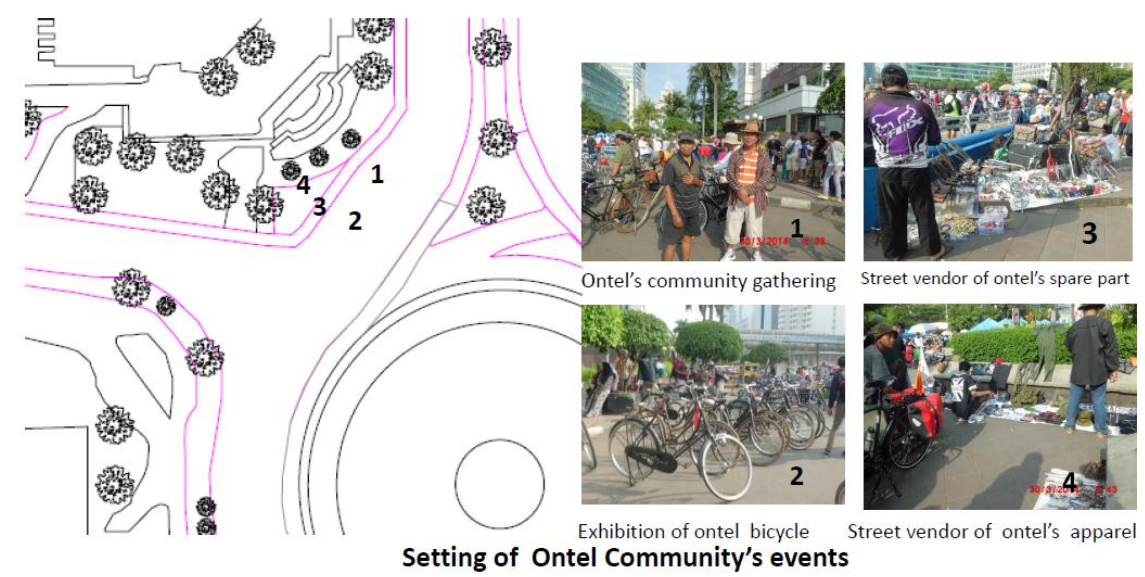

Figure 3 Ontel bicycle community

The existence of this community, as well as their bicycle exhibition, was completed with the presence of traders selling ontel bicycle equipment and spare parts. Traders also sold clothes that are commonly worn by ontel cyclists. This community used the street and pedestrian walkway to gather and exhibit ontel bicycles, while the traders used the pedestrian walkway and fences to display their merchandise. As described by Gibson (1986), the activity of the ontel bicycle community is a small unit within the large unit of the CFD event. Within this small unit, other activities support the ontel bicycle event. In addition to gathering, there are also supporting activities such as exhibition, shopping, and trading. These units are nested and support the main activity, as illustrated in Figure 4.

\subsection{Hierarchy Overlaps among Events and Overlaps within Events}

Figure 3 also shows that in the ontel bicycle community activities, the supporting activities took place close to each other. Bicycle exhibition and selling activities are nested in ontel bicycle event. These activities show the means-ends connection hierarchy in both activities. This can be explained by using Vicente and Rasmussen's (1990) diagram to explore the hierarchy present in these two activities. 


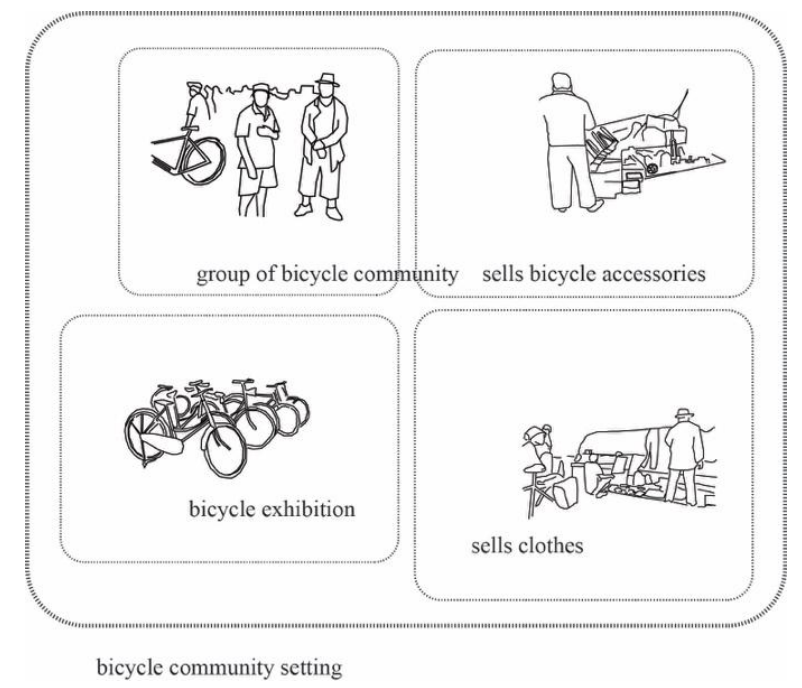

Figure 4 Smaller units within a small unit

What

Figure 5 Hierarchy of the events (based on Vicente and Rasmussen, 1990)

Figure 5 shows that in the ontel bicycle community's activities, there are subordinate activities, such as riding, stopping, carrying, and opening goods. These activities are not interconnected, but are required for the occurrence of activity at the higher level. This means that in the activities of setting up, organizing, and displaying, supporting activities are nested inside them. The diagram also shows that the activities that are the overall objectives of the exhibition and selling activities are the superordinate activities. They will not occur without the activities underneath. The activities of setting up, arranging, organizing, and displaying are nested in the activities above them. Figure 5 also shows a means-ends activity hierarchy that explains the subordinate relationships with mutually supportive superordinates. Some activities will not happen if the spatial configuration is not appropriate and has no affordances. The means-ends hierarchy explains the occurrence of nested events and the connection between spatial configurations with existing events.

Figure 3 shows a variety of the events of the ontel bicycle community members, where gathering is the main activity. As the members communicate, they also show their ontel bicycles to visitors. The existence of this exhibition attracts visitors of the HI Roundabout while the existence of the ontel cyclists triggers the spare parts traders and the clothes traders to attend. This gathering event shows the nested exhibition event as well as the sales event. The activities of arranging the bicycles and merchandise are nested in the exhibition and selling activities. In addition to the sellers, bicycle spare parts, and equipment, the ontel cyclists also attract other visitors who want to look at the bicycles and shop. This fact confirms that these activities occur due to the presence of others. 


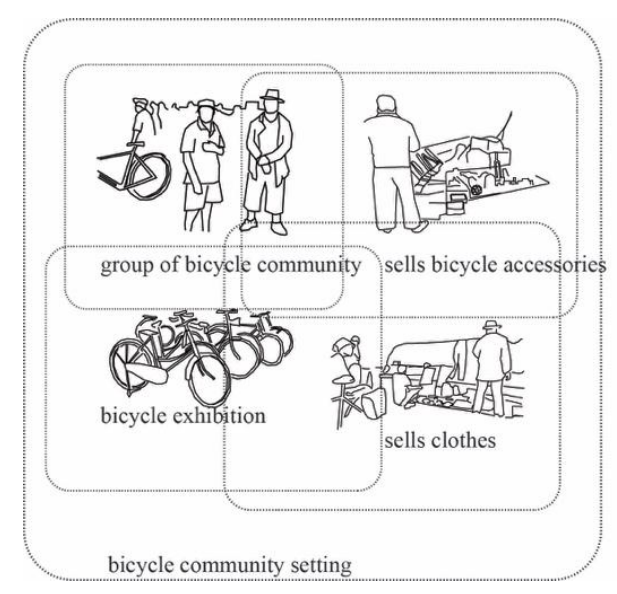

Figure 6 Overlaps among events

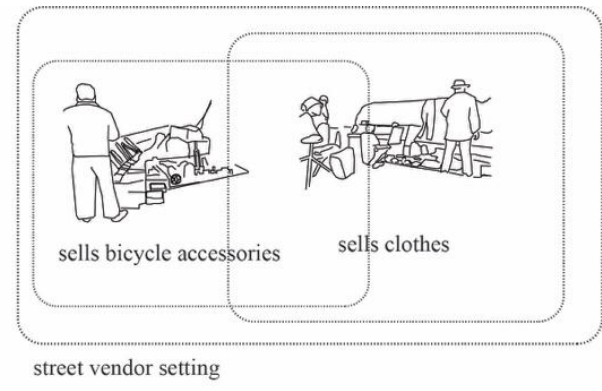

Figure 7 Overlaps within events

As shown in Figure 3, the events of the ontel bicycle community are gathering, communicating, chatting, cycling together, and displaying their antique bikes. They also shop for secondhand ontel bicycle equipment and spare parts. These events use the area around the HI Roundabout and they overlap in the same space. For example, the gathering and exhibition events use the street while the merchants collectively use the pedestrian walkway, fence, and tub plants as their merchandise display areas. Buyers also use the street and pedestrian walkway to move, observe, bargain, and buy. The events created by the visitors, buyers, traders, and members of the ontel bicycle community overlap as they use the same space, as illustrated in Figures 6 and 7.

\subsection{Urban Picnic Spaces Emerge from Nesting Units and Overlaps}

Figure 8 shows various CFD events at the HI Roundabout. Each space and place has a spatial configuration that supports the event in terms of shape, space elements, and social context.

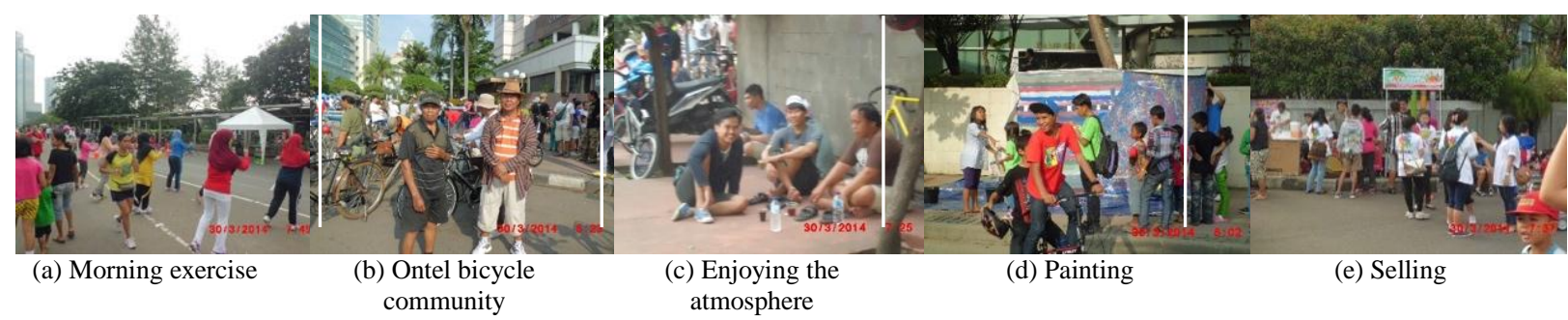

Figure 8 Events at the HI Roundabout

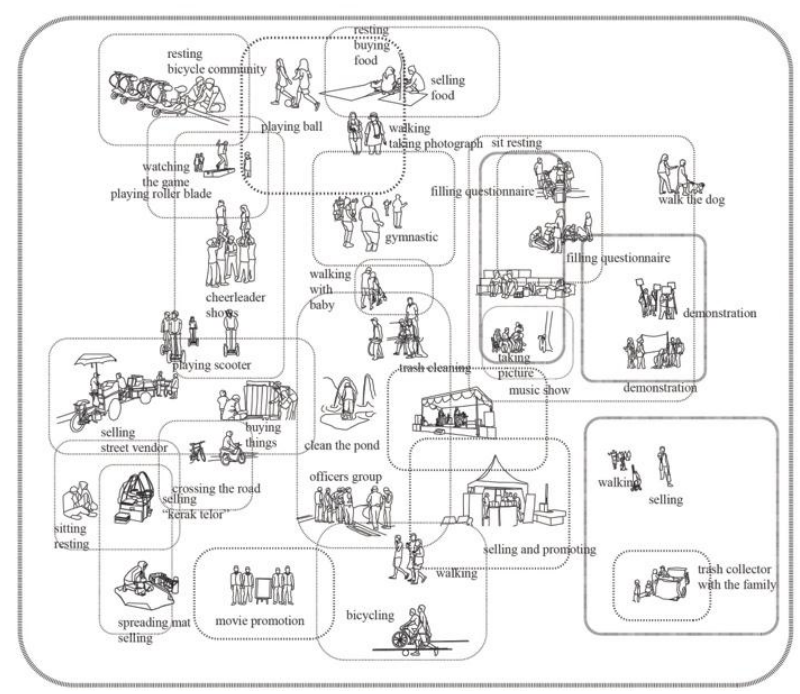

Figure 9 Overlaps within the CFD setting 
In every event, there are nested other events, as described in the previous section. Space usage and the use of space elements overlap. In the CFD event, smaller events use the same space as the street, pedestrian walkway, and pool edges. These events attract each other and there are opportunities for the event or affordance to occur between one event and other events. The CFD event, which takes place in a particular setting, has a variety of events that overlap in their spatial configurations. Spaces that have spatial configurations enable nesting to happen, allowing activities as well as space usage to overlap. The CFD space allows the occurrence of urban picnic events. Figure 9 illustrates the overlapping spatial configurations in space usage and activities/events.

\section{DISCUSSION}

The purpose of this research was to find an alternative to urban space structures, based on the understanding of urban picnic activities in the CFD events in Jakarta. In CFD events, a variety of activities overlap in the space; they are interrelated and provide mutual support to each another. The main findings of the study indicate the occurrence of events within an event, small units within a larger unit, and smaller units within a small unit, as well as the identification of a hierarchy of actions in the events and overlap among the events and units. These findings suggest an alternative way of understanding urban structure that differs from the previous approach of modern urban planning and design.

The modern movement in urban planning and design has its similarities with town planning order in ancient Greece, which used geometrical order (Morris, 1979). Le Corbusier's (1987) idea, called the City of Tomorrow, also used geometrical order. Refers to Forty (2000) order is an attempt to achieve beauty, based on Vitruvius's statement that order is an attainment of beauty as a relationship of parts to the whole. Since the period of the ancient Greeks (Morris, 1979), through the Renaissance (Forty, 2000), and up until the Modern period (Corbusier, 1987), order has been used as an approach to counteract the disorder of cities and obtain beauty. In this study, the findings suggest that there is an order to urban structures, which is not created mainly to obtain beauty, but is based on another form of structure.

This study also offers a different perspective about seeing urban functions. This is different from the idea of the separation of function put forth by CIAM 1928 (Lang, 1994) and Corbusier (1987). Zoning became a way to overcome problems with slums in modern cities (Boyer, 1982). The use of zoning and the separation of urban functions were also proposed by Corbusier (1972) and CIAM 1928 (Lang, 1994). This study found that the separation of function is not as rigid as that used in the modernist idea of urban planning. Events and activities overlap in using space and its elements.

Other ideas about urban planning and design include the vitality, security, and livability of the city. Jacobs (1961) emphasized a mix of uses and the integration of functions. A pedestrianfriendly city center is the key to creating a dynamic and livable city, as suggested by Trancik (1986). Tibbalds (2001) also conveyed the idea of dynamic city life. The Machu Picchu Manifesto (Lang, 1994) aimed to improve the quality of life of urban inhabitants by encouraging the use of public transportation and the preservation of heritage values. Although these approaches attempted to highlight the dynamics of urban life, they did not explain the possible structure of urban space. They only suggested the mix of uses, with no further explanation of how it might actually happen. The current study reveals the use of urban spaces by diverse activities, the overlapping use of spaces, as well as interrelationships and mutual support among the entities. It suggests a different structure of urban spaces.

An attempt to explain the structure of urban space was initiated by Alexander (1965), who studied some modern cities designed as tree structures. He insisted that the city is not a tree because the 
complexity of the social life of the city cannot be represented in a tree structure, where branches and twig with other branches and twigs cannot be interconnected. Therefore, he offered the idea of a semi-lattice structure that can represent the complexity of the social relationships of the citizens and describe the interrelationships and the overlap of activities. He also emphasized that he had not yet found a city designed with the semi-lattice structure. Most cities are designed following the tree structure, which inhibits the freedom of the citizens to interact easily. Alexander (1965) attempted to explain the complexity of relationships in the structure of urban space, especially the linkages in social activities. The current study expanded the understanding of urban structure by using a nesting approach.

A nesting approach (Gibson, 1986) can reveal the structure of urban space used by an urban picnic that is interrelated, supportive, and overlapping. It shows that in a large event, there are nested smaller events, and in a large unit, there are nested smaller units. Through the idea of nesting, we can trace the hierarchy of activities, which support each other through the meansends approach (Vicente \& Rasmussen, 1990). The nesting approach describes the overlap mechanism. It can explain that the structure of a city does not have to be a tree structure (Alexander, 1965). Through nesting, it can be seen that parts of activities or events do not have to be part of the whole, and the parts are not necessarily equal to the whole. The nesting approach can provide opportunities for units or parts to be different. Units can relate to each other freely, without having to go through a hierarchy from small to large or vice versa. As a result, an urban structure with a nesting approach can clearly illustrate the complexity of the relationships that exist in urban spaces. With nesting theory (Gibson, 1986), we can see that each event or unit of activities has its own structure and structures nesting within the structure.

\section{CONCLUSION}

In the case of the urban picnic at the CFD events at the HI Roundabout, we can see that the nesting approach provides opportunities to reveal the complexity of social activities in urban spaces. The nesting approach shows the phenomena of the events nested within an event; the small units nested within a larger unit. We can also look at the differences among the events and units and see the relationships between the entities and units. The relationship is easy and infinite, with or without a hierarchy, and sometimes overlapping. The nesting approach can reveal the structures nesting within the structure and depict the mechanism of the overlapping structures of the units. Therefore, it provides a chance to seek out alternative structures of urban spaces.

\section{ACKNOWLEDGEMENT}

This paper is part of a doctoral dissertation funded by PITTA Grant UI 2017. The field data collection was assisted by Mikhael Johannes, Mikhta Farid, and Tenrita Rizkiaty

\section{REFERENCES}

Alexander, C., 1965. A City is not a Tree. Architectural Forum, Volume 122(1), pp. 58-62

Boyer, C., 1982. Land-use Regulation, is Zoning Compatible with Preservation? In: Cities: The Forces that Shaped Them, Taylor, L., (ed.), Rizzoli International Publications, New York, USA, pp. 70-72

Corbusier, L., 1972. Towards A New Architecture. New York: Praeger Publishers (Original work published 1960)

Corbusier, L., 1987. The City of To-morrow and its Planning (Frederick Etchells, Trans.). New York: Dover Publications (Original work published 1929)

Forty, A., 2000. Words and Building: A Vocabulary of Modern Architecture. London: Thames \& Hudson 
Fuad, A.H., Yatmo, Y.A., 2017. Urban Picnic: Relations Among Actors. Environment-Behaviour Proceeding Journal, Volume 2(5), pp. 239-245

Gibson, J.J., 1986. The Ecological Approach to Visual Perception. New York: Psychology Press Taylor \& Francis Group

Hern, M.E.W., 1989. Picnicking in the Northeastern United States 1840-1900. Winterthur Portfolio, Volume 24(2/3), pp. 139-152

Jacobs, J., 1961. The Death and Life of Great American Cities. New York: Random House, Inc. Lang, J., 1994. Urban Design: The American Experience. New York: Van Nostrand Reinhold

Morris, A.E.J., 1979. History of Urban Form: Before the Industrial Revolutions. London: George Godwin Limited

Regulation of the Governor of DKI Jakarta Province Number 12 Year of 2016

Tibbalds, F., 2001. Making People-Friendly Towns: Improving the Public Environment in Towns and Cities. London: Longman Group UK, Ltd. (Original work published 1992)

Trancik, R., 1986. Finding Lost Space: Theories of Urban Design. New York: Van Nostrand Reinhold

Tschumi, B., 1994. Event-Cities 2. London: The MIT Press

Vicente, K.J., Rasmussen, J., 1990. The Ecology of Human-machine System II: Mediating "Direct Perception" in Complex Work Domains. Ecological Psychology, Volume 2(3), pp. 207-249

Wagman, J.B., Bai, J., Smith, P.J.K., 2016. Nesting in Perception of Affordances for Stepping and Leaping. Attention, Perception \& Psychophysics, Volume 78, pp. 1771-1780 